\title{
Pancreatico-gastric Anastomosis Following Cephalic Duodenopancreatectomy: New Perspectives
}

\author{
Tudor A1,2, Butiurca VO2², Nicolescu C1,2, Tudor Bianca1, Gurzu Simona1', Molnar C1, Copotoiu C11 \\ University of Medicine and Pharmacy Tirgu Mures, Romania \\ 2 Surgical Clinic No. 1, Târgu-Mureș Emergency County Hospital, Mureș County, Romania
}

Introduction. Although in recent years there have been various versions of pancreatic - digestive reconstruction after cephalic duodenopancreatectomy, this issue is still highly debated.

Purpose. This paper aims at comparing postoperative outcomes after gastric pancreatic anastomosis using transfixing threads as opposed to the purse-string suture method.

Material and methods. Our study consisted of a lot of 15 patients that underwent cephalic duodenopancreatectomy from the 1 th of May 2014 to the 30th of April 2015. The pancreatico - digestive reconstruction was done by pancreatico-gastric anastomosis using three different techniques: double purse-string suture used for the patients in the first group (group 1, $n=5$ patients); one purse-string suture and 2 transfixing "U-sutures" passed through the stomach and the pancreas for the patients in the second group (group 2, $n=5$ patients) and ductomucosa anastomosis with pancreatico-gastric transfixing threads in the third group (group 3, $n=5$ patients).

Results. Morbidity was 40\% for the entire lot. Pancreatic fistula, occurred in two patients, one type A fistula in a patient in group 2 and one type B fistula in a patient in group 3. Biliary fistula occurred in one patient in group 2. Mortality was at $13.3 \%$. The median time to carry out the anastomosis in group 1 was 14 minutes, for patients in group 2, 20 minutes, and for patients in group 3, 25 minutes.

Conclusions. Gastric pancreatic anastomosis using purse-string sutures is a feasible, safe and fast process which reduces complications due to transfixing pancreatic threads.

Keywords: pancreatico-gastric anastomosis, double purse string, pancreatic fistula, duodenopancreatectomy

Received: 25 June 2015 / Accepted: 18 July 2015

\section{Introduction}

Improvements in surgical technique and postoperative care decreased the postoperative mortality. In a study by Shailesh V. et al [1], a postoperative mortality of less than $1 \%$ is reported in highly experienced centers [2,3]. However, postoperative pancreatic fistula remains one of the most dreaded complications after duodeno- pancreatic resections $[4,5]$. In a paper presented by Katsaragakis et al [6] pancreatic fistula is reported between $2 \%$ and $40 \%$ [79]. A number of studies have shown that the overall rate of complications is lower after pancreatico-gastric anastomosis as compared to pancreatico-jejunal anastomosis $[10,11]$. In recent years, in order to reduce pancreatic fistulas new surgical techniques were created that have reduced or even avoided transfixing threads passed through the pancreas. In this paper we report the early results of pancreatico-gastric anastomosis following cephalic duodenopancreatectomy performed with and without transfixing threads passed through the residual pancreatic stump.

\section{Material and Methods}

This paper is a prospective study between the $1^{\text {st }}$ of May 2014 and the $30^{\text {th }}$ of April 2015. Data was collected on patients with cephalic duodenopancreatectomy. The study

* Correspondence to: Vlad-Olimpiu Butiurca

E-mail: vladbutiurca@yahoo.com was conducted with the consent of the Ethics Committee of the University of Medicine and Pharmacy Tirgu-Mures.

In this period 15 cephalic duodenopancreatectomies were performed. The pancreatic- digestive reconstruction was achieved with pancreatico-gastric anastomosis. We compared data from patients with anastomosis performed using double purse-string sutures - first group (group 1, $\mathrm{n}=5$ patients) with those that underwent a transfixing threads anastomosis between the stomach and the pancreatic stump. In the group with transfixing threads some of the patients underwent a pancreatico-gastric anastomosis using one purse-string suture and 2 transfixing "U-sutures" passed through the posterior gastric wall and pancreatic stump (group 2, $\mathrm{n}=5$ patients) and the others underwent a duct-to-mucosa anastomosis between the Wirsung duct and the gastric mucosa also using transfixing threads through the seromuscular layer of the posterior gastric wall and the pancreas (group 3, $\mathrm{n}=5$ patients).

The data collected concerned age, sex, type of pancreatico-gastric anastomosis, morbidity, postoperative mortality, any further surgery, operative time and duration of the anastomosis itself, hospital stay. Pancreatic fistula was classified in three levels according to the ISGPF (International Study Group on Pancreatic Fistula): A grade - fistula without clinical impact, $\mathrm{B}$ grade - fistula requiring maintaining fistula drains over a period of three weeks, C grade - fistula requiring another surgery for its management. According 
to the International Study Group on Pancreatic Surgery it is considered a biliary fistula if an externalizing of bile is present on the drains even after 5 days postoperative and operative mortality is considered any death occurring within 30 days after surgery. After finishing the resection, the gastric pancreatic anastomosis was performed using one of the three techniques.

In group 1, following cephalic duodenopancreatectomy a mobilization of the residual pancreatic stump is performed for about $3 \mathrm{~cm}$. The mobilization is followed by a posterior transversal gastrotomy about $2 \mathrm{~cm}$ in length followed by the passage of two purse-string threads at the seromuscular layer (Figure 1) and at the posterior gastric mucosa (Figure 2), around about $1 \mathrm{~cm}$ from the edges of the posterior gastrotomy. This is followed by the placement of two traction threads on the pancreatic stump. Through the distal gastric stump the residual pancreatic stump is pulled gently into the stomach at the level of the posterior gastrotomy so that it will protrude about $2 \mathrm{~cm}$ above the gastric mucosa. The final step is to tighten the external thread of the purse-string followed by the internal one.

For the patients in the second group, the technique consisted of one purse-string suture to the posterior gastrotomy at approximately $1 \mathrm{~cm}$ from the edges of the gastrotomy and after pulling the pancreatic stump into the stomach, two "U-threads" through the stomach and pancreatic stump, above and below the Wirsung duct were placed (Figure 1 and 2).

For the patients in the third group the technique consisted of an incision at the level of the posterior seromuscular layer of the stomach wide enough to be of a suitable length to the pancreatic stump. This is followed by a minimum gastric mucosa incision and a suture with separate threads concerning the Wirsung duct and the gastric mucosa. The final step is a running suture between the incised gastric seromuscular and the capsule and parenchyma of the pancreas.

In all the techniques the Wirsung duct was incannulated with a plastic cannula and secured with resorbable threads. The tube was inserted for a length of about $5 \mathrm{~cm}$ while leaving about $2 \mathrm{~cm}$ outside the duct.

After finishing the pancreatico-gastric anastomosis the process continues with the end-to-side hepaticojejunostomy and the end-to-side gastrojejunostomy.

All patients had a nasogastric tube inserted for the protection of the pancreatico-gastric anastomosis that was maintained until bowel movement resumption. Peritoneal drainage was removed on the 5-7th postoperative day if the drained fluid contained an amylase concentration that did not exceed 3 times the level of concentration serum.

In all patients blood tests and amylase determinations from the drainage tubes was performed.

\section{Results}

Of the 15 patients with cephalic duodeno pancreatectomy, 5 patients underwent pancreatico-gastric anastomosis us-

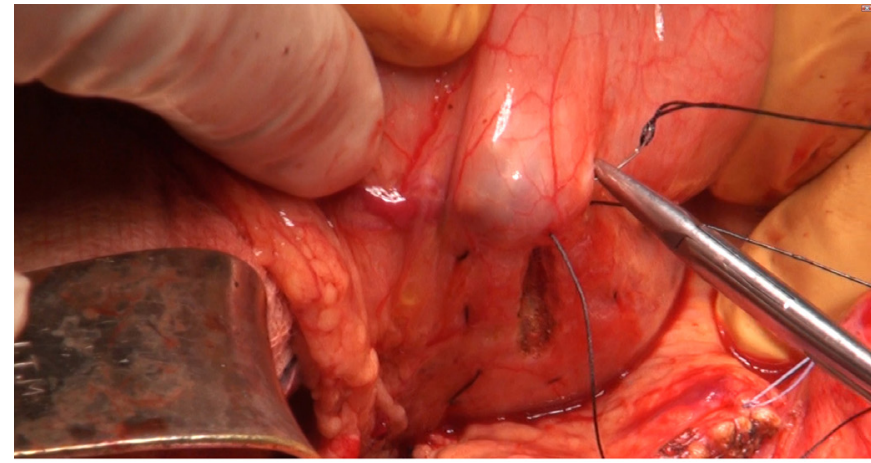

Fig. 1. External purse-string

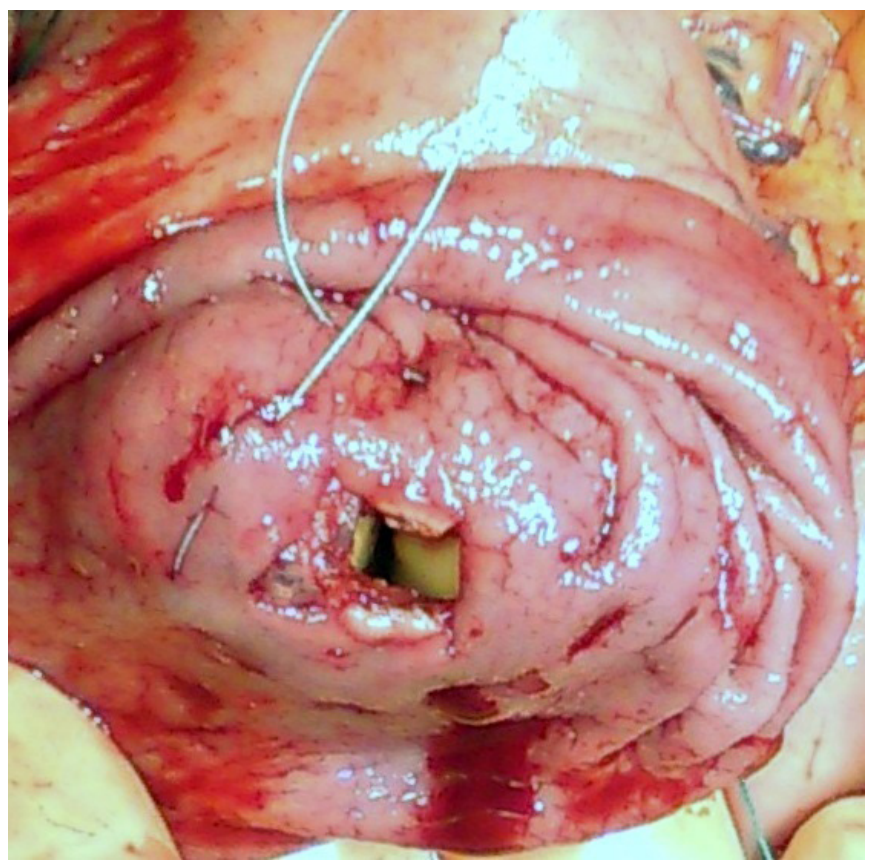

Fig. 2. Internal purse-string

ing double purse-string sutures with no transfixing threads through the pancreas (group 1). On another 5 patients pancreatico-gastric anastomosis was performed using one purse-string thread and 2 transfixing U-sutures through the stomach and the pancreas (group 2), while the last five patients underwent a duct-to-mucosa anastomosis with gastric pancreatic transfixing threads (group 3).

Of all the patients 10 were male and 5 women, aged between 57 and 85 years, median age was 67 years for patients in group 1, 65 for those in group 2, respectively 68 years for the $3^{\text {rd }}$ group. Pancreas of soft consistency was found in 8 cases, the technique used in this instance was pancreatico-gastric anastomosis with double purse-string threads in 5 cases, and in three cases the anastomosis was performed with a single purse-string and two "U-sutures" passed through the stomach and the pancreatic stump.

Histopathology exam revealed pancreatic ductal adenocarcinoma in 10 cases, 3 cases of ampulla adenocarcinoma, one pancreatic serous cystadenoma and one neuroendocrine pancreatic tumor. The median time to carry out the anastomosis in group 1 was 14 minutes, 20 minutes for 
patients in the second group and 25 minutes for patients in group 3 . The median operative time was 180 minute for group 1, 190 minutes for group 2 and 205 minutes for group 3. The median hospital stay for group 1 was 13 days, 18 days for group 2 and 14 days for group 3 .

There were 2 postoperative deaths, in group 2 at a patient with sepsis due to a choleperitoneum and in group 1 a patient due to acute myocardial infarction.

Postoperative complications occurred in 6 patients (40\%) (Table I). Pancreatic fistulas manifested at two patients; A type pancreatic fistula at a patient of group 2, B

Table I. Group based complications following duodenopancreatectomy

\begin{tabular}{lcc}
\hline Group & No. & Complications \\
\hline Group 1 & 2 & $\begin{array}{c}\text { haemoperitoneum by splenic artery lesion } \\
\text { acute myocardial infarction } \\
\text { pancreatic stump bleeding } \\
\text { choleperitoneum } \\
\text { type A pancreatic fistula } \\
\text { type B pancreatic fistula }\end{array}$ \\
\hline
\end{tabular}

type pancreatic fistula at a patient in group 3 , which were solved by maintaining conservative peritoneal drainage.

\section{Discussions}

From the first cephalic duodenopancreatectomy performed by Kausch in 1909, there were numerous techniques that have targeted both the duodeno-pancreatic resection and pancreatico-digestive reconstruction [12].

After Whipple performs the first pancreatico-jejunum anastomosis in 1935, Waugh and Clagett perform the first pancreatico-gastric anastomosis in 1946. This type of anastomosis presents a number of advantages, including: proximity of the two organs, the stomach providing a good support for sutures; the possibility of decompression by nasogastric tube; inactive pancreatic enzymes (due to the acidic environment of the stomach); the possibility of endoscopic management of eventual bleeding from the residual pancreatic stump. There are currently still many controversies regarding the reconstruction of the pancreas with the stomach or the jejunum $[10,13]$. In a study presented by Zovak $\mathrm{M}$ et. al [14] pancreatic fistula and biliary fistula rates are smaller in pancreatico-gastric anastomosis as compared to pancreatico-jejunum anastomosis $[15,16]$. Due to the fragility of the pancreas, pancreatic fistula can occur at sutures sites when transfixing threads are used passed through the parenchyma having a reported rate of $0 \%$ to $18 \%$ in specialized centers [17].

In our study two pancreatic fistulas occurred (13.3\%): one type $\mathrm{A}$ and one type $\mathrm{B}$, both treated conservatively. Type A fistula occurred in one patient in group 2, and the type $B$ in a patient in group 3. A number of factors have been incriminated in the occurrence of pancreatic fistulas, mainly a soft pancreas and a Wirsung duct diameter smaller than $3 \mathrm{~mm}$ [18]. A number of diseases are associated with soft consistency pancreas: Vater ampulla neoplasms, duodenal neoplasms, distal bile duct cancer, neuroendocrine tumors, cystic neoplasms of the pancreas $[19,20]$.

In order to minimize trauma to the pancreatic parenchyma multiple surgical procedures have been described that reduce or even avoid passing threads through the pancreas. Ohigashi uses between 2 and 4 "U-sutures" passed through the remnant pancreatic stump and the posterior gastric wall [21]. In 2009 Peng uses only two double pursestring sutures passed through the seromuscular layer and the mucosal layer of the posterior gastric wall, sealing the pancreatic stump inside the stomach [22]. Subsequently, in 2012, Bartsch describes a technique in which the anastomosis is performed using one purse-string suture on the posterior wall of the stomach and two "U-threads" passed through the wall of the stomach and the pancreatic stump. [23]. Zhu describes a similar technique to Peng applying both of the purse string sutures using only a posterior approach [24].

In our experience pancreatico-digestive anastomosis that avoid transfixing threads are gaining ground. Thus, in the present study, five duct-to-mucosa anastomosis with the use of transfixing pancreatico-gastric threads were performed, five pancreatico-gastric anastomosis similar to Bartsch's procedure using one purse-string thread and 2 "U-threads" passed through the pancreas and the stomach and last but not least 5 pancreatico-gastric anastomosis using two purse string sutures similar to the procedure described by Peng were performed.

The difference between the procedures described by Peng and Zhu is that we do not perform an excision of the posterior gastric seromuscular layer corresponding to the pancreatic stump. Median time for the anastomosis was 14 minutes when performing a double purse string anastomosis compared to 12 minutes as described by Zhu [24]; when performing a technique similar to the one described by Bartsch using one purse string suture and 2 "U-threads" the median time was 20 minutes compared to 18 minutes in Bartsch's study [23].

In our study there were two pancreatic fistula: one type A fistula (patient in group 2) and one type B fistula (group 3).

In his casuistry, Bartsch reports a rate of pancreatic fistulas of $8.6 \%$, while Peng reports one of $0 \%$ [23], and Zhu reports a pancreatic fistula rate of $2.2 \%$ [24]. Because of the well-known friability of the pancreas, we believe that pancreatic anastomosis without transfixing threads will gain numerous followers in the next period.

\section{Conclusion}

The pancreatico-gastric anastomosis using double pursestring sutures is technically simple and avoids the use of transfixing pancreatic threads, thus decreasing pancreatic fistula rates.

\section{Acknowledgement}

This paper is supported by the Sectoral Operational Programme Human Resources Development (SOP HRD), 
financed from the European Social Fund and by the Romanian Government under the contract number POSDRU/159/1.5/S/133377/

\section{References}

1. Shailesh V. Shrikhande, Jörg Kleeff, Markus W. Büchler, Helmut Friess. Pancreatic anastomosis after pancreaticoduodenectomy: how we do it. Indian J Surg. 2007 Dec;69:224-229.

2. Yeo CJ, Cameron JL, Sohn TA, et al. Six hundred fifty consecutive pancreaticoduodenectomies in the 1990s: pathology, complications, and outcomes. Ann Surg. 1997;226:248-257; discussion pp 257-260.

3. Trede M, Schwall G, Saeger HD. Survival after pancreatoduodenectomy. 118 consecutive resections without an operative mortality. Ann Surg. 1990;211:447-558.

4. Reid-Lombardo KM1, Farnell MB, Crippa S, et al. Pancreatic anastomotic leakage after pancreaticoduodenectomy in 1,507 patients: a report from the Pancreatic Anastomotic Leak Study Group. J Gastrointest Surg. 2007;11:1451-1458.

5. Pratt WB, Maithel SK, Vanounou T, Huang ZS, Callery MP, Vollmer CM Jr. Clinical and economic validation of the International Study Group of Pancreatic Fistula (ISGPF) classification scheme. Ann Surg. 2007;245:443-451.

6. Stylianos Katsaragakis, Andreas Larentzakis, Sotirios-Georgios Panousopoulos, et al. A new pancreaticojejunostomy technique: A battle against postoperative pancreatic fistula. World J Gastroenterol. 2013;19:4351-4355.

7. Haddad LB, Scatton O, Randone B, et al. Pancreatic fistula after pancreaticoduodenectomy: the conservative treatment of choice. HPB (Oxford). 2009;11:203-209.

8. Bassi C, Dervenis C, Butturini G, et al. Postoperative pancreatic fistula: an international study group (ISGPF) definition. Surgery. 2005;138:8-13.

9. Butturini G, Daskalaki D, Molinari E, Scopelliti F, Casarotto A, Bassi C. Pancreatic fistula: definition and current problems. J Hepatobiliary Pancreat Surg. 2008;15:247-251.

10. C. Bassi, M. Falconi, E. Molinari, et al. Reconstruction by pancreaticojejunostomy versus pancreaticogastrostomy following pancreatectomy: results of a comparative study. Annals of Surgery. 2005;242:767-773.

11. G. V. Aranha, P. Hodul, E. Golts, D. Oh, J. Pickleman, S. Creech. A comparison of pancreaticogastrostomy and pancreaticojejunostomy following pancreaticoduodenectomy. Journal of Gastrointestinal
Surgery. 2003;7:672-682.

12. Kausch W. Das karzinom der papilla duodeni und seine radikale entfernung. Beitrage zur Klinischen Chirurgie. 1912;78:29-33.

13. Dixon E, Fingerhut A, Bassi C, Sutherland F, McKay A: Metaanalysis of pancreaticojejunostomy versus pancreaticogastrostomy reconstruction after pancreaticoduodenectomy: authors' comment $(\mathrm{Br} J$ Surg. 2006;93:929-936). Br J Surg. 2006;93:1435.

14. Zovak M, Mužina Mišić D, Glavčić G. Pancreatic surgery: evolution and current tailored approach. Hepatobiliary Surg Nutr. 2014;3(5):247-258. doi: 10.3978/j.issn.2304-3881.2014.09.06.

15. Menahem B, Guittet L, Mulliri A, et al. Pancreaticogastrostomy is superior to pancreaticojejunostomy for prevention of pancreatic fistula after pancreaticoduodenectomy: an updated meta-analysis of randomized controlled trails. Ann Surg. 2015;261:882-887.

16. Liu FB, Chen JM, Geng W, et al. Pancreaticogastrostomy is associated with significantly less pancreatic fistula than pancreaticojejunostomy reconstruction after pancreaticoduodenectomy: a meta- analysis of seven randomized controlled trials. HPB (Oxford). 2015;17:123-130.

17. Schäfer M, Müllhaupt B, Clavien PA. Evidence-based pancreatic head resection for pancreatic cancer and chronic pancreatitis. Ann Surg. 2002;236:137-148

18. Callery MP, Pratt WB, Vollmer CM Jr. Prevention and management of pancreatic fistula. J Gastrointest Surg. 2009;13:163-173.

19. Lin JW, Cameron JL, Yeo CJ, et al. Risk factors and outcomes in postpancreaticoduodenectomy pancreaticocutaneous fistula. J Gastrointest Surg. 2004;8:951-959.

20. Poon RT, Lo SH, Fong D, et al. Prevention of pancreatic anastomosis leakage after pancreaticoduodenectomy. Am J Surg. 2002;183:42-52.

21. Ohigashi $\mathrm{H}$, Ishikawa $\mathrm{O}$, Eguchi $\mathrm{H}$, et al. A simple and safe anastomosis in pancreaticogastrostomy using mattress sutures. American Journal of Surgery. 2008;196:130-134.

22. S. Y. Peng, D. F. Hong, Y. B. Liu, J. T. Li, F. Tao, and Z. J. Tan. A pancreas sutureless type II binding pancreaticogastrostomy. Zhonghua Wai Ke Za Zhi. 2009;47(23):1764-1766.

23. Bartsch DK, Langer $P$, Kanngiesser V, Fendrich V, Dietzel K. A simple and safe anastomosis for pancreatogastrostomy using one binding purse-string and two transfixing mattress sutures. Int J Surg Oncol. 2012:718637.

24. Feng Zhu, Min Wang, Xin Wang, et al. Modified Technique of Pancreaticogastrostomy for Soft Pancreas with Two Continuous Hemstitch Sutures: A Single-Center Prospective Study. J Gastrointest Surg. 2013;17:1306-1311. 